\title{
Is it Morally Right to Commit Suicide?
}

\author{
Yiwen Huang
}

\author{
Hunan Gongshang University \\ yw.huang@protonmail.com
}

\begin{abstract}
Suicide, as a highly controversial issue, has yet to gain legitimacy and moral justifiability. This issue is still worth discussing due to different personal preferences and their influences. The author will mainly focus on the definition of suicide and defend the idea that suicide is morally right in some circumstances. The author's research method is theoretical, including literature review and philosophical reasoning, and also provides arguments and definition of hypotheses. The author might gives a possible but relatively reasonable definition of suicide behaviour, and discuss the correctness of suicide behaviour through argumentation.
\end{abstract}

Keywords: suicide, utilitarianism, Kantian, desire, burden, identification

\section{INTRODUCTION}

This article has three purposes. Firstly, to make a definition of suicide. The author will start by studying a range of examples in order to gain a better understanding of suicide because what is suicide is still controversial. Secondly, the author will defend the view that suicide is morally right under some circumstances, Thirdly, the author will make moral evaluations of suicide from a utilitarianism's perspective. The author conclude that suicide should be a spontaneous act; Moreover its evaluation should be based on an individual's identification with desires rather than the moral contradiction caused by different views people hold on suicidal behaviours. Discussions and views the author provided in this article might help people morally accept the correctness of suicide behaviour in some circumstances.

\section{A DEFINITION OF SUICIDE}

In this section, the definition of suicide will be discussed. People judge suicide in a variety of ways depending on different factors. Some might base their judgements on their own moral and non-moral knowledge, experiences, and feelings. But this still falls very far short of reaching a reasonable definition for suicide. People might be properly confined to the reliance on moral codes, but tend to avoid confronting the critical issue, which is how to define the right to life and self identity. According to Cholbi[1]: "Suicide is a controversial ethical issue in large part because the reasonings of (a) and (b) above appear plausible but support contradictory conclusions. (a) in effect asks: Why should we be granted an exemption to the prohibition on human killing when the person we kill is ourselves? What makes killing oneself so special? (b) on the other hand starts from the intuition that there is something special or distinctive about the moral relationship we stand in to ourselves, a relationship that can at least sometimes morally justify suicide."

The lack of a definition of suicide has led to people's misunderstandings about suicide. Here are some examples. First, the author would like to discuss an 'accidental but predictable' self-caused death. Assume Joe was an alpinist and he was climbing a snow-covered mountain alone which has never been successfully climbed before, then an avalanche comes. He has nowhere to go or hide. The only thing Joe can do is wait for death. In this case, what Joe actually does is giving up his life. Does Joe responsible for his own death? It is conformed that Joe was the one who chose to undertake this adventure. However it is uncertain whether his behavior means suicide. Death was not what Joe was after in terms of the goal, motive, process and result. What is most important is that Joe himself was not physically and psychologically the executioner of his death, the avalanche is. Joe did not initiate the action of giving up him life to death and am only forced to accept the result passively. As a consequence, it seems problematic and counter intuitive to consider himself as someone committing suicide in this case. 
Based on the example above, if the author makes a few changes, the outcome would be totally different. Imagine that Joe was stranded, facing the avalanche alone. After he realized that whatever efforts he made, such as digging a hole in the snow to buy me some more minutes, the final consequence is still my death. Thus, Joe decided to shoot himself to avoid the suffering from struggling on the brink of death. Now things have changed completely - he commits suicide, with no doubt about it. Moreover, because death is his goal and he identify with the outcome, he was the executioner himself both physically and psychologically.

The third example the author would like to mention is voluntary euthanasia. Generally speaking, , committing to voluntary euthanasia is also a proactive decision made by those disabled, critically-injured people who suffer from incurable diseases and have only a very short time remaining. The following is a typical example[8]:

On the 5th of August, 1993, Thomas W. Hyde Jr., a suffering of Lou Gehrig's disease (ALS), was brought to Dr. Jack Kevorkian's 1969 Volkswagen Bus - his residence - to be assisted in suicide. Providing Hyde with a mask connected to a tube of carbon monoxide, Kevorkian gave Hyde a string which, when pulled, released a paperclip holding the gas from filling the mask, which subsequently resulted in Hyde's death, twenty minutes after being pulled. A video tape made on the 1st of July, 1993, showed that Hyde desired the procedure, with him stating explicitly, "I want to end this. I want to die." Hyde was the 20th person Kevorkian helped to kill.

A a possible objection could be that in the case of voluntary euthanasia, one would normally authorize a qualified person, maybe a doctor, to carry out the execution, so they do not essentially cause their own death. That's exactly what happens in those countries who recognize the legality of voluntary euthanasia. But does this really matter? The author would reject this. The vital factor is not whether the way you commit suicide is direct or indirect. If a person decides to voluntarily euthanize, what vital factors are:

(1) whether he or she identified with the outcome (death).

(2) whether his or her death is entirely and completely of his or her own making of decision and mean.

(3) whether he or she is on free will.

Then the author might be able to provide a definition of suicide based on the examples and interpretation the author gave above. Suicide can be defined as:

(S)An action is a case of suicide If and only if a person is completely identified with an ultimate goal(s), and commits physical self-destructive proactively and willingly to achieve it.

With this definition, the author might be able to have the scale of my discussion limited, to focus on the specific definition of suicide as above.

\section{REPLIES TO THE VIEW THAT SUICIDE IS MORALLY WRONG}

When discussing suicide, people often mention some relevant factors, such as motivation, deliberation, action, and the result. The author might not be able to avoid involving factors like motivation and influence. But the author will not focus on all those factors. What the author will do is to keep this discussion within the proposed definition of suicide [7](S).

An objection to an ordinary case about suicide which could be firstly considered is that, assume one is a person who has suffered from critical mental illness for decades. In his personal opinion, the only way out of this pain is to commit suicide. This case is quite similar to that of Thomas W. Hyde Jr's that the author mentioned above. Hardwig's opinion seems plausible, especially when he is the only worker in his family and their lives might be in trouble without him[3]. This leads us to the conclusion that suicide is wrong because it will place burdens on the living. But, the author would like to discuss this issue from a different perspective, since Hardwig fails to consider what the person who commits suicide thinks. In this case, there is a conscious avoidance of the issue of the position that the act of suicide does place burdens on the family and loved ones from the perspective of the suicidal person's family. But what will happen when people reconsider it from the perspective of the person who commits suicide? It is obvious that the situation is completely reversed. It is his family and his loved ones who are placing the burden on him. In this circumstance, he needs to bear more than he could bear, and part of these burdens comes from his family, that is, they want him to continue to live and bear the paint of disease which obviously not what he want.

Now the author considers another view about suicide from Kant[4], who also rejects the plausibility of suicide. He claims that:

"Act in such a way that you treat humanity, whether in your own person or in any other person, always at the same time as an end, never merely as a means."

Although suicide is very unlikely to pass Kant's first formulation. It could pass Kant's second formulation. According to Kant's second formulation, people should consider dignity and respect when treating humanity. Here is the argument: 
(i): According to Kant, treat humanity:

Always as an end is morally right;

Merely as a means is morally wrong;

(ii) He was in a huge amount of pain and his only way out is to commit suicide;

(iii): Although suicide is a mere means because his ultimate goal is to get eternal peace and avoid pain, it also means that he treat his humanity as an end, and with respect

(iv): According to Kant's second formulation, he has done nothing wrong because, in this case, humanity is still treated properly and respectfully;

(v) From discussions above, researchers can conclude that suicide is morally right.

This argument provides guidance theoretically and practically. According to this argument, (v) is plausible even though it is intuitively controversial. If people wish to show their respects and defend one's dignity, then people should be clear about whose dignity should be given priority. In this case, the author tend to compromise by treating both suicidal person and his family with respect and protecting their dignity.

The argument the author made above make a strong case that, even if people don't consider about the priority issue(i.e. whose dignity should be considered in the first place), or people treat all sides equally, and according to my understanding, suicide is still morally permitted by Kant's second formulation, at least to some extent. Kantians will not easily reject (i), (ii), (iii), (iv), although it might be quite difficult for them to accept (v).

The third objection which claims that there is a type of suicide that it is 'wrongful, self-regarding based' because these kinds of suicidal people find that things in their lives have lost their value[5], so this kind of suicide was driven by mistaken belief. The author does not quite agree with this opinion. The reason why Kupfer said this is, as "I" understand it, it is an irrational and reckless act for someone to commit suicide because they are desperate or disappointed with their life or the things in it. Even so, in a case like this, the author does not think people can judge the rightness of suicide so easily. The author accepts that suicide itself is a kind of state of chaos, but as observers, if people make judgements on such grounds alone, then people are likely to be trying to play the role of ideal observer because we believe that our moral standard are indisputably correct and question other's view of life and value, which the author has no doubt that no one can do. It is highly possible that, one, and maybe the only practical solution people can provide, is to $\mathrm{m}$ those who want to commit suicide act according to their own will, to fulfill their self-interest. This makes suicide morally correct.

\section{AN UTILITARIAN EVALUATION OF SUICIDE}

In this section, the author will try to make an evaluation of suicide from a utilitarian perspective. Utilitarianism suggests that it is morally good if an act brings about the maximum net balance of happiness. The first question to ask is: how much good can the act of suicide produce or how much bad can it prevent? The author might not be able to measure the accurate amount of good that suicide can create, but utilitarianism did provide us with some other methods.

The author will take the mental illness case that the author mentioned before as an example. People might never know what exactly the consequences are after one commits suicide, since people are properly confined to a lack of moral and non-moral knowledge. But it is obvious that the first thing most of us will notice is that life is fading. Then people start to concern about his family, his loved ones, until people notice that they have left out the most important thing: a tortured man was finally relieved. Here is a specific example of a mentally ill person: the extraordinaire writer Ernest. M. Hemingway who suffered from a mental disease. He had been fighting against the disease for decades. Drugs, alcohol, electroshock therapy, all these so-called treatments were wearing him down. Finally, he chose to commit suicide to relieve himself of pain.

Hemingway's case is exceptional, but when others are faced with such a situation, regardless of the degree of pain, the assumption is that the pain is more than the individual can bear although these days with current medicine the pain is usually manageable. What should they do? A possible answer is that, they have no choice but to choose what they believe to be the best option among all. This will create the greatest amount of good for both victims and their families and loved ones - if they really care about each other - regardless of whether their belief is correct or not, the point is to choose the 'best option' since we are all in lack of moral and nonmoral knowledge.

But what is the best choice? and how can they understand what the strongest desire is? From the author's perspective, since utilitarianism is very demanding, the author may not able to consider all consequences, and the author may not be able to measure good easily due to lack of moral and non-moral knowledge. Besides, some claims that suicide is neither rational nor irrational because future is a non-existent thing for the suicidal person, and it is not necessary to judge the rationality of his suicide since both 'rational' and 'irrational' are all future-oriented[2]. This means that the rationality of suicide is not our concern for now. 
Thus, what they should do is to follow the first step of the process of determining optimific, that is, to identify what is intrinsically good for both the suicidal person and their family and loved ones. If an act of suicide is a must-do, its harm can be minimized and its benefits can be maximized in advance, by identifying what is intrinsically good, to create the greatest amount of good over misery. This sort of defence still followed the principle of utilitarianism although it leans towards subjectivism literally.

The suicide behaviour itself can be considered as an event, or as an action that is a reflection of a series of reasons. But from the author's perspective, it is more like a dilemma, a more complicated one since it involves too many indicators. Further, unlike other dilemmas, for instance, the trolley problem or plank of Carneades, suicidal behaviours are closer to reality and its preconditions are varied and sometimes unpredictable, which makes suicide victims suffer from their problem and external pressures at the same time. Also, it is difficult for them to consider this problem from the perspective of bystanders due to the individual's uniqueness, vice versa. In the author's view, the question 'what is the best choice' sometimes can be set aside temporarily. What should be concerned most, or a more precise interpretation might be, "Is there any better choice than to commit suicide in this circumstance?" This question does imply that committing suicide is simply a bad choice to some extent. The cost of suicidal behaviour, if its scope of influence is reduced to an individual, is the fading of life, or it means permanent physical and mental damage, which makes it a costly thing that human beings cannot bear. But this does not simply mean that suicide is wrong. Indeed, utilitarians can not provide an even imprecise way to measure good, or provide a quantified smallest unit of a good, to respond to the question above directly. But utilitarians believe that no action is intrinsically wrong or right since its morality is completely dependent on its outcome. In the case of suicide, it is critical to note that, no matter how awful the outcome of suicide behaviour is, it is still permissible because it can always provide the necessary means to prevent an even worse outcome.The author would like to present two examples to explain more about the author's stance on suicide:

(EA): Modified electroconvulsive therapy $(\mathrm{mECT})$ is a psychiatric treatment to manage refractory mental disorders. People who suffer from these kinds of diseases usually have suicidal tendencies, the cause of which might be due to their disease or side effects of drugs. The mECT might cause cognitive impairment such as persistent or permanent memory loss. If a person with a mental disorder wants to commit suicide, is it a good idea to stop her and treat her with mECT, even if she will lose her precious memories? Which one is more important for an individual, her mind or her life?
(EB) Assume John has suffered from bipolar disorder. He has a strong tendency to attack others when his emotions are out of his control. He commits suicide. Is his behaviour morally right?

In the author's view, there is no doubt that (EA) is a little bit controversial because we cannot easily judge which is more important, the body or the spirit. But it still shows that when facing the suicide issue, what morality tells us is vague. For (EB), the case is set very concisely, with almost no additional conditions. The author would say it is quite plausible to say John's behaviour is morally right because his behaviour, or the outcome of his behaviour, prevented further damage and fulfilled his needs at the same time. According to utilitarianism, it shows that suicide has its moral legitimacy and correctness.

\section{CONCLUSION}

Suicide itself, including its motivations, moral legitimacy, and all other consequences and influence, is still highly controversial. In this article, the author made a definition of suicide which points out that people who commit suicide should first be identified with their ultimate goal, then also commit suicide proactively and willingly. In author's view, suicide is not a vice, but a morally right action under certain circumstance.To defend this, the author made two argument based on Kant's second formulation, the first argument respond to the 'burden' issue and the second one might provide a possible way to deal with the 'priority' issue. In the final part, the author tried to evaluate suicide based on utilitarianism, showing that it is possible to explain the 'selectivity' issue based on utilitarianism.

\section{REFERENCES}

[1] Cholbi, M. Suicide: The Philosophical Dimensions. Broadview Press, 2011.

[2] Cowley, C. "Suicide Is Neither Rational nor Irrational." Ethical Theory and Moral Practice, vol. 9, no. 5, 2006, pp. 495-504.

[3] Hardwig, J. "Is There a Duty to Die?" The Hastings Center Report, vol. 27, no. 2, 1997, pp. 34-42.

[4] Kant, I. Lectures on Ethics. Translated by Louis Infield. Hackett Publishing Company. 1963.

[5] Kupfer, J. "Suicide: Its Nature and Moral Evaluation." The Journal of Value Inquiry, vol. 24, no. 1,1990 , pp. 67-81.

[6] Philip A. P.Medical Ethics,Queensborough Community College, The City University of New York, https://www.qcc.cuny.edu/socialsciences/ppecorin o/ - MEDICAL_ETHICS_TEXT/index.html., 2002. 